IFN Working Paper No. 1157, 2017

\title{
Misvaluation and Financial Constraints: Method of Payment and Buyer Identity in Mergers \& Acquisitions
}

Aron Berg 


\title{
Misvaluation and financial constraints: method of payment and buyer identity in mergers \& acquisitions
}

\author{
Aron Berg *
}

March 15, 2017

\begin{abstract}
The paper studies how stock price misvaluation and financial frictions affect whether an acquisition occurs between or within industries and whether the acquirer pays in cash or stocks. I set up a model where stock market misvaluation correlates within industries and across industries and assume that managers have private information regarding their own firm and firms similar to it. The model yields predictions regarding which firm acquires which firm, and the method of payment used in transactions.

Keywords: Mergers and acquisitions; investments; asymmetric information; stock misvaluation; financial frictions.

JEL classification: D82, G32, G34.
\end{abstract}

${ }^{*}$ Research Institute of Industrial Economics (IFN), P.O. Box 55665, SE-102 15 Stockholm, Sweden, and Lund University, Department of Economics, School of Economics and Management, P.O. Box 7082, SE-220 07 Lund, Sweden, aron.berg@ifn.se.

Acknowledgement: I gratefully acknowledge financial support from the Jan Wallander and Tom Hedelius Foundation, the Marianne and Marcus Wallenberg Foundation, and Vinnova. 
Counting from the late 19th century, more than half of all mergers have clustered in short so-called "merger waves" (Kolev, Haleblian and McNamara, 2012). For example, both the 1960s and the 1980s saw much lower merger activity during the first years of the decades than they did during the latter years, and the average yearly value of deals announced during the Dotcom years in the late 1990s was double the average value in the years after the stock market dropped. At the same time, merger waves differ from on to another: In the 1960s, acquirers and targets were usually from different industries, while the wave of the 1990s occurred within industries. Also, while stock payments were common in the 1960s and the 1990s, cash payments dominated the 1980s (Andrade, Mitchell, and Stafford, 2001; Shleifer and Vishny [SV], 2003).

In this paper, I contribute to the theoretical merger-wave literature by furthering the understanding of what determines whether acquirers and targets are from the same industry and whether the acquirer pays with cash or stocks. I do this within a framework of stock-market misvaluation and costly external financing. The model predicts that unrelated merger waves (i.e., mergers waves between industries) occur when the stock market is overvalued, and that the payment in these waves will consist primarily of stocks. Industry-level misvaluation increases a firm's likelihood of undertaking stock-financed acquisitions of unrelated firms, but it has a weaker effect on the likelihood of acquiring firms in the same industry. For financial constraints, the model predicts that reducing financing costs increases the number of unrelated mergers, and reducing financing costs has a greater effect on merger activity during times of market undervaluation than it has during times of market overvaluation.

The model builds on Rhodes-Kropf and Viswanathan (RKV, 2004) where the basic setup is an auction with several bidders and one target. RKV divide firms into two groups: one that can only make stock bids, and one that can only make cash bids. The difference between the two payment forms is that the "true value" of stock bids is not known; due to private information, managers know more about their own firms' values than the stock market knows, causing misvaluation of the firm's stocks. The key assumption is that this "misvaluation" correlates 
within industries. RKV show that correlation in firms' misvaluation causes merger waves to occur because managers of targeted firms will overestimate the true value of stock bids during times when all firms are overvalued.

I modify RKV's model in three ways. First, I let bidders be from different industries (including from the target's own industry) with misvaluation correlating both between and within industries. ${ }^{1}$ Second, I assume that managers' private information allows them to better estimate the value, not only of their own firm, but also of similar firms (firms in the same industry). Third, I let all bidders make both stock and cash bids, but I associate cash bids with an opportunity cost.

The modifications allow for new predictions, and change some of the predictions from the original model. Due to the first two changes, marketwide overvaluation (overvaluation that applies to all firms in the stock market) causes an increase in stock financed mergers between unrelated firms, but not between related ones. The reason for this is that in a more overvalued market, targeted firms are more likely to err by overestimating stock bids from unrelated firms, something that does not apply to stock bids from related firms since managers' private information allows them precise estimates of related firms' true values. For the same reasons, sector-specific overvaluation (overvaluation that applies to all firms in a specific sector) has a stronger effect on unrelated mergers than it has on related mergers. In both cases, more mergers occur because overvaluation allows acquirers to purchase the target's assets at a discount in terms of their true value. These predictions differ from RKV's who make no prediction regarding a differentiated effect of marketwide overvaluation on related and unrelated mergers, and who predict that both related and unrelated mergers increase with sector overvaluation. Allowing all firms to make both stock and cash bids, allows me to investigate how changes to financing conditions affect merger activity. Since cash payments avoids the problem of asymmetric information (misvaluation) and asymmetric information is a larger problem between indus-

\footnotetext{
${ }^{1} \mathrm{RKV}$ consider the case where the bidders are from a different industry than the target, but they do not consider several industries (including the target's industry) simultaneously.
} 
tries, reducing the cost of external financing increases the number of unrelated mergers. Furthermore, due to the cost associated with cash bids, firms only pay by cash if the target ends up undervaluing their stock offer. This is more likely to occur when the market is undervalued, so reducing the cost of external financing has a greater effect on merger activity during these times than it has during times of overvaluation.

Apart from RKV, the most closely related article is SV, who also studies the role misvaluation may have in creating merger waves and affecting the choice of payment. SV assume that there is no informational asymmetry between firms, but that there exist an agency problem between managers and shareholders. In their model, a difference in the misvaluation of acquirer and target is necessary for stock financed mergers, so an increase in the misvaluation of all firms do not lead to more mergers. Empirically, my model's prediction with regard to marketwide overvaluation differ from SV's since it predicts that marketwide overvaluation will be associated with an increase in unrelated mergers (but both models predict that there will be no effect on related mergers), and they differ in a similar manner in their predictions on firm-specific overvaluation. However, the models make the same predictions for sector-specific overvaluation: Firms in overvalued sectors will conduct more stock-financed acquisitions of unrelated firms, but not of related ones, and targets are more likely to come from undervalued sectors.

The paper relates to the literature on merger waves and on method of payment in mergers and acquisitions. Several papers study merger waves as a rational response to changing economic circumstances, where economic chocks or technological innovations create profitable opportunities to reallocate assets between firms (e.g., Gort, 1969; Mitchell and Mulherrin, 1996; Jovanovic and Rousseau, 2002, 2008). Other papers study the effects of asymmetric information on the method of payment as a separate topic. This literature clarifies the varying reasons why acquirers choose to pay with cash or stocks, and when targets accept these as payment (see, e.g., Hansen, 1987; Fishman, 1989; Eckbo, Giammarino, and Heinkel, 1990; Berkovitch and Narayanan, 1990; Gorbenko 
and Malenko, 2014). I contribute to this literature by studying how the payment method varies with merger activity, and how the effects of financial constraints vary with stock-market misvaluation.

The next section provides the model setup. The section following it solves for equilibrium bidding strategies, and provides results regarding the target's evaluation of bids. Section 3 derives results concerning the identity of the acquirer and the method of payment, connecting these to misvaluation and the cost of external financing. Finally, Section 4 concludes the paper.

\section{The model}

The basic setup and timing of the model is as follows. The model begins with several potential acquirers targeting a single firm for a takeover. To decide which, if any, of the potential acquirers will buy the firm, the targeted firm arranges an auction. The auction mechanism is that of a second-price auction; that is, the firm with the highest bid wins, and pays the value of the secondhighest bid. Furthermore, the auction is in two parts: In the first stage, the potential acquirers make bids with stocks and the target decides on a winner. In the second stage, losing bidders can challenge the winning stock bid by putting forth a cash bid at least as good as the winning stock bid. If any bidder puts forth such a cash bid, a new second-price auction starts where all firms bid cash. $^{2}$

The model assumes that managers try to maximize the true/long-term value of their stockholders' wealth. So, with perfect information, stocks and cash are perfect substitutes. However, it is reasonable to assume that managers possess private information regarding their own firms, meaning that their estimate of their own firm's value does not coincide with the estimate made by other agents. I will model this asymmetry with three assumptions. The first assumption is that managers possess superior information with regard to the prospects of their

\footnotetext{
${ }^{2}$ Liu (2012) uses a two-stage auction where the second stage is triggered only if any bidder is willing to outbid the winner in the first stage.
} 
firm and can therefore make a better or more accurate estimate of the firm's true worth. Second, the private information that the manager possesses also allows her to make a more accurate estimate of similar firms. Third, the fact that the market does not have access to private information leads it to put a different value on the firm, and this "misvaluation" made by the market (as compared to the valuation made by the manager of the firm) is correlated between firms, particularly those in the same industry.

Under asymmetric information, accepting a stock payment is risky for the target manager since she does not know the true value of such bids, in contrast to cash offers (cash is cash, and its value is known). Thus, if there are no financial frictions, a bidder only prefers to pay in stock if it is overvalued, something that the target manager would know. Therefore, I assume that it is costly for bidders to pay in cash. The assumption is natural in a setting of asymmetric information (see, e.g., Stein, 2003), and it allows a rational target manager to accept stocks as payment. ${ }^{3}$

The model consists of three types of agents: the target firm, bidding firms, and the market. I consider the acquisition of only one, already given firm, which I denote by $T$. That is, I abstract from bidders searching for a target, and the effect of the potential to acquire other targets on the "outside option" of potential acquirers. ${ }^{4}$ That is, the model starts in a setting where potential acquirers have already "found" a target and investigates how firm characteristics ought to affect which firm (if any) wins and the method of payment. On the bidding side, there are $n$ potential acquirers $(\mathcal{I}=\{1,2, \ldots, n\})$ sorted into $m+1$ industries $(\mathcal{K}=\{\mathcal{T}, 1,2, \ldots, m\})$, where $\mathcal{T}$ denotes the industry of the target firm. ${ }^{5}$ The managers of all firms are risk neutral, and there are no agency problems between manager and stockholders. The final agent is "the market." The market does not participate in the auction, but it is important in its role

\footnotetext{
${ }^{3}$ Vermaelen and $\mathrm{Xu}(2014)$ find that targets accept stock payments if stock payments are motivated by the bidder's capital structure.

${ }^{4}$ This last assumption means that the misvaluation between firms is correlated both within and across industries.

${ }^{5}$ If firm $i$ belongs to the same industry as the target, I write this as $i \in \mathcal{T}$.
} 
of pricing (and mispricing) stocks.

Every firm has true a value, $X_{i}$, that is observed by the firm's own manager (more correctly, $X_{i}$ is the manager's best prediction of the true value). However, this knowledge is not only conditioned on public information, but also on information private to the manager. The market does only have access to private information, so in general the market's estimate (the market value, $M_{i}$ ) will differ from the true value, $X_{i}$. To allow for correlation within and across industries, I follow RKV's approach and specify the market value of firm $i$ as

$$
X_{i}=M_{i}\left(1-\varepsilon_{i}\right)\left(1-\psi_{k}\right)(1-\rho) .
$$

Here $\varepsilon_{i}, \psi_{k}$, and $\rho$ are a firm-specific, industry-specific and a marketwide mispricing factor, respectively. All mispricing factors are assumed to be independently and identically drawn from continuous zero-mean distributions denoted $F_{\varepsilon}(\varepsilon), F_{\psi}(\psi)$, and $F_{\rho}(\rho)$. Following RKV I assume that $\log \left(1-\varepsilon_{i}\right), \log \left(1-\psi_{k}\right)$, and $\log (1-\rho)$ have $\log$-concave distributions. Since the market value of a firm cannot be negative, the support of the mispricing factors must lie on $(-\infty, 1)$, and the zero mean implies that some of the range must be nonnegative. ${ }^{6}$ As implied by the names, the firm-specific mispricing factor is unique to the individual firm, all firms in the same industry share the industry-specific factor, and all firms in the market share the marketwide factor. So if $\psi_{k}>0$, then industry $k$ is overvalued and $\rho>0$ implies that the whole market is overvalued - effectively inducing correlation in the misvaluation within and between industries. That the mispricing factors are drawn i.i.d. means that the market prices the firms correctly on average - i.e., the market price is the best estimate of a firm's true value given the public information $(E[X \mid M t]=M)$.

RKV discuss the interpretation of the misvaluation and the motivation for dividing it into separate components. One interpretation is that managers have superior information with regard to the future prospects of the firm. Superior

\footnotetext{
${ }^{6}$ Note that the market valuation increase relative to the true value and whenever any of the mispricing factors increases. That is, $\left(1-\varepsilon_{i}\right)\left(1-\psi_{k}\right)(1-\rho)<1$ implies that the firm is overvalued.
} 
information allows a manager to make a better prediction about her firm's true value compared to the market $\left(X_{i}\right.$ rather than $\left.M_{i}\right)$, but the manager is not sure how this information relates to other firms. However, the manager can surmise that some of her private information should be relevant to other firms; for example, seeing a drop in demand for her own firm, the manager might suspect that some of this drop is due to weakening aggregate demand and, thus, that the value of all firms should be affected. Nevertheless, managers do not know which parts of or to what extent their private information carries over to other firms. Thus, even if managers know the value of the whole misvaluation factor $\left(1-\varepsilon_{i}\right)\left(1-\psi_{k}\right)(1-\rho)$, they do not know how this is divided among the different subfactors - i.e., they do not know if it is the market, the sector, or just they themselves that are over/undervalued. Another interpretation offered by RKV is that $\psi_{k}$ and $\rho$ are mispriced factors shared by industries and the market, while the mispricing factors $\varepsilon_{i}$ are not.

In contrast to RKV, I assume that the managers of a firm can also predict how their information relates to their direct competitors. This informational advantage is different from that modeled by RKV. RKV does not assume that managers have a direct informational advantage as compared to the market, but that there exists an indirect advantage because the firms share misvaluation factors. For example, if the market overvalues a firm by 10\%, the manager might estimate that $3 \%$ of this is overvaluation of the firm itself, $3 \%$ is overvaluation of the industry, and the remaining $4 \%$ is due to an overvaluation of the entire market. The manager then adjusts her expectation of all other firms by adjusting their market value accordingly. However, the manager adjusts her valuation of other firms in an identical fashion - she adjusts the market prices by her estimates of the common mispricing factors. My assumption is that managers make individual predictions for the firms that they know the most about - their rivals. For example, a producer of smart phones who receives a private signal about faltering demand for premium phones may conclude that this new piece of information is worse news for Competitor A, which specializes in premium phones, than it is for Competitor B which has most of its sales in 
the budget segment. If this were the case, the rational manager would revise her estimate of A's and B's true values differently, not just scale both of them by the same factor. In the model, I make the highly stylized assumption that the managers make the same update as the rivals themselves - i.e., they know their rivals' true value. While unrealistic, this simplification serves as a contrast to the aforementioned case and highlights the effects of having an informational advantage.

Shared misvaluation is important when firms make stock bids since it will affect the target's valuation of the bids. For cash bids, misvaluation does not have any direct effect since the value of cash is known. Instead, I assume that firms are financially constrained - i.e., that firms cannot freely access cash to finance investments. I incorporate this into the model by splitting the firms' true values into two parts, $X^{\mathrm{A}}$ and $X^{\mathrm{O}}$, where

$$
X^{\mathrm{A}}+X^{\mathrm{O}}=X .
$$

$X^{\mathrm{O}}$ represents a firm-specific opportunity cost for paying in cash, that is, if acquirer $i$ pays the target's shareholders in cash, the acquirer's stand-alone value drops from $X_{i}$ to $X_{i}^{\mathrm{A}}$. Introducing an explicit cost for paying with cash allows me to conduct comparative statistics on how changes to the financial constraint affect firms differently depending on how financially constrained they already are. Furthermore, it allows me to show how the effect of lowering the opportunity cost is stronger when the market is undervalued.

Since I have assumed that managers aim to maximize stockholders' true value, and since stock acquisitions are associated with misvaluation and cash acquisitions with opportunity costs, the possibility of real overall gains needs to exist. I follow RKV and let bidder $i$ 's valuation of acquiring the target be

$$
V_{i}=\left(1+s_{i}\right) X_{\mathrm{T}} .
$$

Here $s$ is the synergy effect associated with $i$ taking over the target. Every bidder is assumed to know its own valuation of the target, and while it does not know either $X_{\mathrm{T}}$ or $s_{i}$, it is common knowledge that $s$ is drawn i.i.d. from 
a distribution $F_{s}(s)$, with $\log \left(1+s_{i}\right)$ having a log-concave density function. One way to think about this setup is that the bidders know target's assets and how to use them if they acquire the target - i.e., they know what they get in an acquisition and its value to them $(V)$. However, due to asymmetric information, the bidders do not know how the target is currently using its assets or how it intends to use the assets in the future, and hence they do not know the true value the assets have under the current ownership $\left(X_{\mathrm{T}}\right)$. In the model, it is of no consequence to the bidding firms that they do not know the true value of the target - the only thing that matters is their own valuation. This

private-value setup eliminates the motivation for stock payment as a way of sharing "overpayment costs" (if the target's assets are of poor quality). This, in combination with stock misvaluation, means that we need to have some sort of opportunity cost of cash for there to be both stock and cash acquisitions.

To determine which firm (if any) becomes the acquirer, and how it pays, the outcome is decided through a two-stage second-price auction. In the first stage, bidders submit stock bids consisting of a fractional claim to the combined firm. Due to misvaluation, the target manager does not take the bids at face value, but instead uses all available information to estimate which bid is the highest. After picking a winner in the stock auction, as well as the "price" to be paid, the auction moves on to its second stage, where all bidders can instead post cash bids to rival the winner of the stock auction. If there exists no cash bid that exceeds the expected value of the winning stock bid, the winner from the first stage wins the whole auction and pays the agreed upon shares.

\section{Equilibrium bids and the target's decision}

Before analyzing the outcome of the model, we need to establish how firms bid and how the evaluation of the bids is connected to misvaluation. In this section, I establish the potential acquirers' equilibrium bids and describe how misvaluation affects how the target evaluates stock offers. The section shows how the perceived value of a bid changes due to misvaluation and, thus, highlights the 
role of the informational advantage of the target when evaluating bids from its own industry. The section begins by considering stock bids before moving on to cash bids. The section for stock bids draws on a corresponding section in RKV's paper. For two of the proofs, I direct the reader there. However, it is necessary to include this section for two reasons. The first reason is to comprehend some of the model's mechanics, allowing the reader to understand the remainder of the analysis. The other reason is that some of the lemmas differ between the papers due to assumption differences.

\section{$2.1 \quad$ Stock bids}

In the stock auction, interested buyers offer bids consisting of stocks in their respective firms. In the model, bidders offer to buy the target's assets in exchange for a fraction $(\alpha)$ of the shares in the combined firm; that is, bidder $i$ 's offer entitles the target's shareholders to the fraction $\alpha_{i}$ of $i$ 's existing assets as well as the fraction $\alpha_{i}$ of the acquired assets. Since the manager of the target considers the long-term interest of her shareholders, she attempts to choose the bid with the highest true value. This is where the problem occurs: The manager does not observe the true values of the bids. Instead, she has to make her decision based on estimates. So how does the manager do this? The true value of a bid equals $\alpha(X+V)$ (where $X+V$ is the true value of the bidder if it acquirers the target), and since managers consider the long-term interest of their shareholders, the target manager determines the stock-auction winner based on her conditional expectation of $\alpha(X+V)$. The ranking thus follows the cardinality of $E\left[\alpha_{i}\left(X_{i}+V_{i}\right) \mid \Phi_{\mathrm{T}}\right]$, where $\Phi_{\mathrm{T}}$ is the target's information set.

That the expectation is taken with respect to the target manager's information set is crucial. In the absence of any private information, the best estimate of a firm's true value is its market value - i.e., the market value, $M$, is the expectation of $X$ conditional on all public information. However, when the target evaluates the bids, it has two additional sources of information: its private signal and the size of incoming bids. 
First, consider the effect of the private signal. To begin with, since firms are able to predict how their private information relates to other firms in the same industry, the target knows the true value of bids from its industry peers. While the target manager is not able to do this for firms of other industries, she can still use the knowledge about her own misvaluation to "correct" the market's valuation of these firms. For example, consider the case when the target firm is overvalued. The target's manager only knows that the firm is overvalued, but she does not know whether this is due to an overvaluation of the firm itself (through $\varepsilon_{\mathrm{T}}$ ), its industry $\left(\psi_{\mathrm{T}}\right)$, or of the entire market $(\rho)$. As a Bayesian updater, the manager puts some weight on all three of these possibilities - expecting all misvaluation factors to be positive - and updates her expectations of other firms' true value accordingly. That is, the manager revises her expectation of the true value of all firms in the market downward by the appropriate amount, from $M$ (the best prediction of $X$ given no public information) to something less than $M$. Effectively, this means that all bids will look less appealing than they would in the absence of the target's private information.

The second set of new information consists of the bid sizes. A bid can be high in terms of market value for two reasons: 1) The bid is actually large - i.e., the bidding firm is actually willing to pay a great deal in terms of real value to acquire the target's assets; 2) the market overvalues the bidder's stock, inflating the apparent value of the bid. Therefore, upon receiving a bid, the target does not take it at face value, but instead uses its knowledge about the distributions of the misvaluation factors and the synergy to get a new estimate of the true value of the bid. Hence, when the target evaluates and ranks the bids, it does so based on

$$
\Phi_{\mathrm{T}}=\left\{\alpha_{i}, M_{i} \forall i, X_{j} \forall j \text { if } j \in \mathcal{T}, M_{\mathrm{T}}, X_{\mathrm{T}}\right\}
$$

That is, the target incorporates information about its own misvaluation $\left(X_{\mathrm{T}}\right.$ and $\left.M_{\mathrm{T}}\right)$, the true value and misvaluation of its industry peers $\left(X_{j}, M_{j} \forall j\right.$ if $\left.j \in \mathcal{T}\right)$, 
and the "size" of all bids $\left(\alpha_{i}, M_{i} \forall i\right)$, into its decision.

In RKV, all bids are scored symmetrically since all errors and synergies are independent. Since my model includes firms from different industries, this assumption is no longer valid, and I will only assume that symmetrical scoring applies within an industry. This assumption is made for within-industry scoring rather than for the whole market, because of the industry-specific misvaluation factor, $\psi_{k}$. That the market price contains all public information about a firm's true value motivates ranking bids from the same industry symmetrically because these firms all have the same shared-misvaluation factors. All information regarding the shared components of firm $i$ 's misvaluation can be applied to the estimate of $i$ 's industry peers, but only some of this is applicable to firms in other industries. Based on the information she gets from $i$ 's bid, the target manager will thus revise her estimate of bids from $i$ 's industry differently than she will revise other bids. For example, upon observing a large fraction of high bids from industry $k$, the target manager estimates that this is due to the sector being overvalued and thus, that their bids only appear to be high. The target manager adjusts her expectations of the true value of bids from sector $k$ accordingly, but if the manager believes that the overvaluation is due to sector overvaluation, then it makes no sense to adjust the estimates of firms in other sectors. $^{7}$ In the end, this means that identical bids (i.e., in the duple $(\alpha, M)$ ) are not scored symmetrically if they are from different industries.

When a winner has been chosen, the "price" is determined by the target's estimate of the second highest bid. Letting subscript 1 refer to the firm with the highest estimated bid, and subscript 2 to the runner up, the share, $\hat{\alpha}_{1}$, that the winner must pay is determined by

$$
\begin{aligned}
& E\left[\hat{\alpha}_{1}\left(X_{1}+V_{1}\right) \mid \hat{\alpha}_{1}, M_{1}, \alpha_{2}, M_{2}, \Phi_{\mathrm{T}-}\right] \\
= & E\left[\alpha_{2}\left(X_{2}+V_{2}\right) \mid \alpha_{2}, M_{2}, \hat{\alpha}_{1}, M_{1}, \Phi_{\mathrm{T}-}\right],
\end{aligned}
$$

where $\Phi_{\mathrm{T}-}$ is the target's information set without the two "top bids." In words:

\footnotetext{
${ }^{7}$ More precisely, the target will adjust the bids from other sectors as well because it will put an increased probability on the overvaluation of the whole market. This will also affect the bids from industry $k$.
} 
$\hat{\alpha}_{1}$ is the smallest fraction that the winning firm could have bid and still won the auction.

RKV shows that the assumption of independent and log-concave distributed errors and synergies means that the expected value of firm $i$ 's bid increases with $\alpha_{i}$. Furthermore, increasing $\alpha$ decreases the expected value of all competing bids because increasing the size of the bid will increase the target's expectation of the shared misvaluation factors. Together this implies that a firm is more likely to win if it increases its bid, which allows RKV to show that the standard result of truthful bidding in a second-price auction also holds in this setup; that is, in equilibrium, all firms bid their true valuation of the target's assets: ${ }^{8}$

$$
\alpha_{i}=\frac{V_{i}}{X_{i}+V_{i}} .
$$

Given this result, the target's problem boils down to choosing the bidder it believes to have the highest valuation of the target's assets, that is, the ranking of bids follows $E\left[V_{i} \mid \Phi_{\mathrm{T}}\right]^{9}$

That bidders bid their true valuation of the target does not mean that the problem of asymmetric information disappears - the target is still unable to distinguish a bid that is truly high from one that only appears high. Nevertheless, "truthful bidding" means that a bid constitutes a signal regarding the bidder's valuation and misvaluation. RKV show that the statistic $\frac{\alpha_{i}}{1-\alpha_{i}} M_{i}$ ranks the bids in their setup, and that the target therefore ranks the bids in the same order as does the market. However, these results do not apply when bidders are from several different industries or the target knows the true value of its industry peers. Instead, we have Lemma 1.

Lemma 1 If the misvaluation factors and synergies are independently distributed and have log-concave densities, then

$$
E\left[V_{i} \mid \alpha_{i}, M_{i}, \Phi_{\mathrm{T}}\right]=E\left[V_{i} \mid \frac{\alpha_{i}}{1-\alpha_{i}} M_{i} \forall i, X_{j} \forall j \text { if } j \in \mathcal{T}, X_{\mathrm{T}}, M_{\mathrm{T}}\right]
$$

\footnotetext{
${ }^{8}$ To get the truthful-bidding result, it is not necessary for the expected value of competing bids to fall when $i$ increases its $\alpha_{i}$ - it is sufficient that the change in the expected value of $i$ 's bid is more positive.

${ }^{9}$ If $\alpha_{i}=\frac{V_{i}}{X_{i}+V_{i}}$, then $E\left[\alpha_{i}\left(X_{i}+V_{i}\right) \mid \Phi_{\mathrm{T}}\right]=E\left[V_{i} \mid \Phi_{\mathrm{T}}\right]$.
} 
and $\frac{\alpha_{i}}{1-\alpha_{i}} M_{i}$ and $X_{j} \forall j$ if $k=T$ are sufficient statistics to rank the bids.

Proof. The proof is a simple extension of RKV.

Corollary 2 The market's ranking of the bids is (generally) not the same as the target's ranking of the bids.

Proof. The best the market can do is to rank the bids according to

$$
E\left[V_{i} \mid \frac{\alpha_{i}}{1-\alpha_{i}} M_{i} \forall i, M_{\mathrm{T}}\right] .
$$

Lemma 1 stated that the statistic $\frac{\alpha}{1-\alpha} M$ is a sufficient statistic to rank the bids within an industry. The market thus ranks bids from other industries differently from the target industry in the same order as the target, but since the target observes the true value of bids from the same industry, it will (in general) give these bids a different rank.

Given that the target knows the true value of bids from its industry peers, it is no surprise that its ranking of these bids will differ from the market's ranking. However, if I dispense of this assumption, $\frac{\alpha_{i}}{1-\alpha_{i}} M_{i}$ is still not a sufficient statistic because the target's knowledge of its own misvaluation allows a more accurate estimate of the shared misvaluation factors and, thus, of the bids' true values. Using the relationship between $X_{i}$ and $M_{i}$ in (1), and the result that bidders bid their true valuation (equation (6)), the statistic $\frac{\alpha_{i}}{1-\alpha_{i}} M_{i}$ simplifies to $\frac{\left(1+s_{i}\right)}{\left(1-\varepsilon_{i}\right)\left(1-\psi_{k}\right)(1-\rho)}-$ i.e., it is the ratio of the bidder's synergy to its misvaluation. The lemma thus states that the target cannot determine whether a bid is truly high, or just appears high due to misvaluation. Hence, $\frac{\alpha_{i}}{1-\alpha_{i}} M_{i}$ rank bids within an industry, but knowledge about the target's misvaluation $\left(X_{\mathrm{T}}\right.$ and $\left.M_{\mathrm{T}}\right)$ can change the ranking between industries. ${ }^{10}$

Lemma 1 tells us that misvaluation affects the ranking of bids, but it does not specify how the estimated value of the bids is affected. Consider, for example,

\footnotetext{
${ }^{10}$ This means that if $i$ and $j$ come from the same industry, then $Z_{i}>Z_{j}$ (i.e., $i$ 's bid is given a better score) if and only if $\frac{\alpha_{i}}{1-\alpha_{i}} M_{i}>\frac{\alpha_{j}}{1-\alpha_{j}} M_{j}$. However, if they are from different industries, this relationship does not necessarily hold. Similarly, if $j$ is from the same industry as the target (so that its valuation is known), then $\frac{\alpha_{i}}{1-\alpha_{i}} M_{i}>V_{j}$ does not imply that $i$ 's bid is ranked higher than $j$ 's bid.
} 
an increase in the marketwide misvaluation. The increase makes all bids seem larger, but it also leads to a greater overvaluation of the target, causing the target to expect the marketwide misvaluation to be higher. To determine which effect dominates, I need to rewrite the target's information set $\left(\Phi_{\mathrm{T}}\right)$. It turns out that we can rewrite the information set as a collection:

$$
\begin{gathered}
\frac{\left(1+s_{i}\right)}{\left(1-\varepsilon_{i}\right)\left(1-\psi_{k}\right)(1-\rho)}, \\
\frac{\left(1+s_{i}\right)\left(1-\varepsilon_{j}\right)\left(1-\psi_{l}\right)}{\left(1-\varepsilon_{i}\right)\left(1-\psi_{k}\right)\left(1+s_{j}\right)} \forall j \neq i \text { and } j \in l \in \mathcal{K}, \\
\left(1+s_{j}\right) \forall j \text { if } j \in \mathcal{T}, \\
\frac{\left(1+s_{i}\right)\left(1-\varepsilon_{\mathrm{T}}\right)\left(1-\psi_{\mathrm{T}}\right)}{\left(1-\varepsilon_{i}\right)\left(1-\psi_{k}\right)}
\end{gathered}
$$

Note that all I do is transform the variables using equations (1) and (6); that is, nothing has been added or subtracted from the information set. What is important is that all elements are now functions of the synergy or the misvaluation factors. Since the target knows the distributions of these factors, Lemma 3 holds.

Lemma 3 Given the assumption of log-concave densities, the random variables $\left(1+s_{i}\right), \frac{\left(1+s_{i}\right)}{\left(1-\varepsilon_{i}\right)\left(1-\psi_{k}\right)(1-\rho)}, \frac{\left(1+s_{i}\right)\left(1-\varepsilon_{j}\right)\left(1-\psi_{l}\right)}{\left(1-\varepsilon_{i}\right)\left(1-\psi_{k}\right)\left(1+s_{j}\right)} \quad \forall j \neq i$, and $j \in l \in \mathcal{K},(1+$ $\left.s_{j}\right) \forall j$ if $j \in \mathcal{T}$, and $\frac{\left(1+s_{i}\right)\left(1-\varepsilon_{\mathrm{T}}\right)\left(1-\psi_{\mathrm{T}}\right)}{\left(1-\varepsilon_{i}\right)\left(1-\psi_{k}\right)}$ are affiliated.

\section{Proof. See RKV. ${ }^{11}$}

An affiliation between variables $X$ and $Y$ means that a higher value of $Y$ implies a higher distribution of $X$ in the sense of first-order stochastic dominance. For conditional expectations, this implies that the expectation of $X$ conditioned on $Y$ is increasing in $Y$.

Before turning to how misvaluation affects the auction outcome, I need to solve the second stage of the auction where firms bid with cash. ${ }^{12}$

\footnotetext{
${ }^{11}\left(1+s_{i}\right)$ and $\left(1+s_{j}\right)$ are independent of each other and therefore affiliated. The proof for the other factors extends from the proof in RKV.

${ }^{12}$ Milgrom and Weber (1982) examine the role of affiliation in auctions of incomplete information. Caplin and Nalebuff (1991) discuss implications and applications of log-concavity in economic theory.
} 


\subsection{Cash bids}

After the stock-bidding part of the auction, the target is committed to accepting the winning bid. At this stage, no profitable stock offers can challenge the winner; all firms have bid their true value so no one is willing to increase her offer. However, it might be the case that the target "wrongly" undervalues a firm with high synergies - i.e., the target expects that the misvaluation affecting the bidder is higher than it actually is and therefore puts a too low value on its stocks. In this case, the bidder can choose to make a cash offer to rival the winning stock bid. ${ }^{13}$

Unlike stock offers, asymmetric information does not plague cash offers cash is cash, and everyone knows its value. The problem is that the bidders do not have costless access to cash. This means that the bidders' value of acquiring the target is reduced by the opportunity cost and becomes $V-X^{\mathrm{O}}$. Lemma 4 then applies under the second-price auction mechanism.

Lemma 4 All firms bid their true value of acquiring the target with cash, that is, all firms bid $V_{i}-X_{i}^{\mathrm{O}}$.

Proof. Let $C_{i}$ denote firm $i$ 's cash bid. If the firm wins, then its net gain from the acquisition is

$$
V_{i}-X_{i}^{\mathrm{O}}-C_{2}
$$

That is, the target's net value to firm $i\left(V_{i}\right)$, minus the opportunity cost of using cash $\left(X_{i}^{\mathrm{O}}\right)$ and the second highest bid $\left(C_{2}\right)$. To maximize its profit, $i$ solves

$$
\max _{C_{i}} E\left[\left\{V_{i}-X_{i}^{\mathrm{O}}-C_{2}\right\} 1_{\left\{\max _{\forall j} C_{j} \leq C_{i}\right\}} \mid X_{i}^{\mathrm{A}}, X_{i}^{\mathrm{O}}, V_{i}\right]
$$

where $1_{\{\cdot\}}$ is an indictor function that takes the value of one if the condition in the subscript is fulfilled. ${ }^{14}$ Since it is a second-price auction, the value for $i$ from

\footnotetext{
${ }^{13}$ Empirically, it has been shown that cash is more likely to be used when two or more bidders compete for the same target (see, e.g., Eckbo, Makaew, and Thorburn 2016).

${ }^{14}$ Note that if there is only one cash bidder, then $C_{2}$ is the target's expected value of the winning bid in the stock-bidding part of the auction. If no stock offer was deemed good enough, it is $C_{2}=X_{\mathrm{T}}$ - i.e., the target's stand-alone value.
} 
actually winning the auction is not dependent on its bid; the bid only affects the chance of winning, not its payment when winning. Thus, if $C_{i}>V_{i}-X_{i}^{\mathrm{O}}$, then reducing $C_{i}$ to $V_{i}-X_{i}^{\mathrm{O}}$ only eliminates instances where winning the auction would entail a negative payoff to $i$, and if $C_{i}<V_{i}-X_{i}^{\mathrm{O}}$, then increasing $C_{i}$ to $V_{i}-X_{i}^{\mathrm{O}}$ only adds instances where winning the auction yields a positive payoff. Therefore, it is a dominant strategy for $i$ to bid $C_{i}=V_{i}-X_{i}^{\mathrm{O}}$.

If no cash bid exceeds the expected value that the target puts on the winning stock bid, the winner from the first stage wins and pays the agreed upon fraction of its firm.

\section{Acquirer identity and the method of payment}

This section uses the previous results to investigate when the acquirer and target are more likely to be from the same industry and when the acquirer is more likely to pay with stocks rather than cash.

The target manager is obliged to act in the long-term interest of her shareholders, so a deal only occurs if the manager believes it benefits the shareholders in the long run. That is, a merger occurs if there is at least one bid that the target estimates to be worth more than the firm's stand-alone value. In the stock auction, this means that there exists a bid $i$ such that

$$
\alpha_{i} E\left[X_{i}+V_{i} \mid \Phi_{\mathrm{T}}\right] \geq X_{\mathrm{T}}
$$

since the left-hand side is the expected value of firm $i$ 's bid. However, since there is a chance that someone challenges the stock-auction winner, this is only a necessary condition for a stock acquisition, not a sufficient condition. So when does a challenge happen? The auction enters the cash-bidding stage if a bidder puts forth a cash bid that is higher than the target manager's estimate of the winning stock bid. The natural question to begin with is, thus, "What is the target manager's valuation of the winning stock bid?" Equation (5) stated that the winning bidder must pay a fraction $\hat{\alpha}_{1}$ of its shares, where $\hat{\alpha}_{1}$ is defined as the minimum fraction the winner could have bid to just tie the second highest 
bid. The target manager thus estimates the value of the winning bid to be

$$
\hat{\alpha}_{1} E\left[X_{1}+V_{1} \mid \Phi_{\mathrm{T}}\right]=\alpha_{2} E\left[X_{2}+V_{2} \mid \Phi_{\mathrm{T}}\right],
$$

or $X_{\mathrm{T}}$ if there is only one firm above the target's reservation value. ${ }^{15}$ Using Lemma 4, the auction only enters the cash stage (and thus leads to a cash acquisition) if a bidder exists such that ${ }^{16}$

$$
V_{i}-X_{i}^{\mathrm{O}} \geq \Lambda \equiv \max \left\{E\left[V_{2} \mid \Phi_{\mathrm{T}}\right], X_{\mathrm{T}}\right\}
$$

The condition in (13) is sufficient for a cash acquisition. A stock acquisition occurs if the target finds at least one stock bid good enough and no firm advances a cash offer to challenge it (i.e., if (12) holds but (13) does not hold). This yields the first results for the method of payment.

Lemma 5 All cash-bidders are undervalued by the target manager.

Proof. The easiest way to prove this is by showing that if the target overvalues a bidder, there is no cash bid that is profitable to the bidder, and then show that such bids can exist when the target undervalues the bidder. Lemma 4 showed that every bidder's dominant strategy is to bid its true valuation in the cash auction (i.e., to bid $V-X^{\mathrm{O}}$ ). Since a firm will only make a cash offer if it is profitable, $V_{i}-X_{i}^{\mathrm{O}} \geq \Lambda \equiv \max \left\{E\left[V_{2} \mid \Phi_{\mathrm{T}}\right], X_{\mathrm{T}}\right\}$. Consider first the case where the bidder does not win the stock auction but finds it profitable to make a cash bid. Necessarily,

$$
\begin{aligned}
V_{i}-X_{i}^{\mathrm{O}} & \geq \Lambda \equiv \max \left\{\alpha_{2} E\left[X_{2}+V_{2} \mid \Phi_{\mathrm{T}}\right], X_{\mathrm{T}}\right\} \\
& \geq \alpha_{i} E\left[X_{i}+V_{i} \mid \Phi_{i}\right]=E\left[V_{i} \mid \Phi_{i}\right]>V_{i},
\end{aligned}
$$

\footnotetext{
${ }^{15}$ If only one bid is deemed to be higher than the stand-alone value, the winner must pay the fraction $\hat{\alpha}_{1}$ such that $\hat{\alpha}_{1} E\left[X_{1}+V_{1} \mid \Phi_{\mathrm{T}}\right]=X_{\mathrm{T}}$.

${ }^{16}$ Here, I use that truthful bidding in the stock auction implies $\alpha_{2} E\left[X_{2}+V_{2} \mid \Phi_{\mathrm{T}}\right]=$ $E\left[V_{2} \mid \Phi_{\mathrm{T}}\right]$. The condition also incorporates the situation where the target estimates that all stock bids are below its stand-alone value $\left(X_{\mathrm{T}}\right)$. In this case, a cash bidder has to bid above the stand-alone value of the target.
} 
where the last inequality follows from the bidder being overvalued by the target manager. However, this is a contradiction since $X_{i}^{\mathrm{O}} \geq 0$. Similarly, for the winner of the stock auction to prefer paying with cash,

$$
V_{1}-X_{1}^{\mathrm{O}}-\hat{\alpha}_{1} E\left[X_{1}+V_{1} \mid \Phi_{\mathrm{T}}\right]>V_{1}-\hat{\alpha}_{1}\left(X_{1}+V_{1}\right)
$$

but this contradicts that $X_{1}^{\mathrm{O}} \geq 0$ and $E\left[X_{1}+V_{1} \mid \Phi_{\mathrm{T}}\right]>\left(X_{1}+V_{1}\right)$.

Finally, if firm $i$ is undervalued, then $\left(X_{i}+V_{i}\right)>E\left[X_{1}+V_{1} \mid \Phi_{\mathrm{T}}\right]$ (and $V_{i}>E\left[V_{i} \mid \Phi_{\mathrm{T}}\right]$ ); so, if the synergy is high enough (and the opportunity cost of cash low enough), it is profitable for the firm to offer a cash bid.

The first proposition follows immediately from this lemma.

Proposition 6 Firms from the same industry as the target never pay with cash.

Proof. Since the target firm knows the true value of other firms in its industry, the proposition follows from Lemma 5 .

If $i$ loses the stock auction, the payment the winner must pay is estimated (by the target) to be greater than the estimate of bidder $i$ 's bid (equal to the estimate if $i$ is the runner up). Thus, if the target manager does not undervalue $i$, the reservation price in the cash auction must be greater than $i$ 's valuation of the assets because of truthful bidding. Within-industry mergers are never finalized using cash because the target manager knows the true value of these firms and, hence, the true value of their bids. While this assumption might seem extreme, evidence suggest managers know more about firms that are similar to their own, and that they therefore are more likely to accept stock payments in mergers (Eckbo, Makaew and Thorburn, 2016). If I dispense of this assumption and instead go to the other extreme - i.e., that they just observe the firms' market value, then Proposition 6 is nullified and Lemma 5 is the relevant result also for within-industry mergers. Note that Lemma 5 does not say that cash bidders are undervalued by the market - what is important is whether the target undervalues them. Situations where the target undervalues the bidder but the market overvalues it can occur when the target itself is overvalued, or when the market's overvaluation of other bidders is high. In both instances, the target 
will make a more forceful downward revision of all bids. Furthermore, since paying with cash is costly, it can still be profitable for a winning firm to stick to its stock offer even when the target undervalues its shares.

The above results say nothing about the probability of a merger actually occurring, nor when we should expect a merger to occur within industries. For this purpose, and to determine how the method-of-payment pattern relates to misvaluation, I turn to how misvaluation affects the target's evaluation of the stock bids.

Proposition 7 A more overvalued market (i.e., a greater value of $\rho$ ) yields a greater probability of i) a merger occurring, ii) the merger being between industries, and iii) the merger being paid in stock.

Proof. i) Because the target manager attempts to maximize the long-term value of the shareholders, she accepts any bid with an expected value greater than the stand-alone value, $X_{\mathrm{T}}$ (or accepts the highest bid if there is more than one bid that exceeds the stand-alone value). Using the expression in (12) and the definition of $V_{i}$ in (3), this implies that a stock merger may occur if

$$
E\left[V_{i} \mid, \Phi_{\mathrm{T}}\right]>X_{\mathrm{T}} \Longleftrightarrow E\left[\left(1+s_{i}\right) \mid \Phi_{\mathrm{T}}\right]>1
$$

for some $i$. The only conditioning factor in the target's information set affected by market misvaluation is $\frac{\left(1+s_{i}\right)}{\left(1-\varepsilon_{i}\right)\left(1-\psi_{k}\right)(1-\rho)}$, which increases in $\rho$. According to Lemma 3, this means that the expectation of the synergy is increasing in the market-misvaluation factor. Thus, it is more likely that any bid will exceed the target's reservation price when the market is overvalued. Since misvaluation does not affect bidders' willingness to pay in the cash auction, the probability of an acquisition increases with the market misvaluation.

ii) Bids from the target's own industry are unaffected by misvaluation. This means that the probability of a merger increases because it becomes more likely that an outside bid is deemed good enough by the target. At the same time, there will be cases where a bidder from the target industry would have won if the 
marketwide misvaluation were lower, but loses when it is increased. Altogether, this increases the share of between-industry mergers.

iii) Cash is the method of payment iff at least one bidder has a net gain from a cash acquisition higher than the reservation price in the second-stage cash-acquisition auction - i.e., if the inequality in (13) holds for some $i$. Since $V_{i}=\left(1+s_{i}\right) X_{\mathrm{T}}$ and $s_{i}$ are independent of $X_{\mathrm{T}}$ and $X_{i}^{\mathrm{O}}$ (firm $i$ 's alternative cost), we have

$$
\begin{aligned}
& \mathbb{P}\left\{\left(1+s_{i}\right) X_{T}-X_{i}^{O} \geq \Lambda\right\}=\mathbb{P}\left\{s_{i} \geq \frac{\Lambda+X_{i}^{O}}{X_{T}}-1\right\} \\
& =1-F_{s}\left(\frac{\Lambda+X_{i}^{O}}{X_{T}}-1\right),
\end{aligned}
$$

where $F_{s}(\cdot)$ is synergy's cumulative density function. Since the synergy factors are assumed to be drawn independently from each other, the probability of any firm offering a cash bid is

$$
\begin{aligned}
& \mathbb{P}\left\{\left(1+s_{i}\right) X_{T}-X_{i}^{O} \geq \Lambda \text { for some } i\right\} \\
& =1-\prod_{i=1}^{N} F_{s}\left(\frac{\Lambda+X_{i}^{O}}{X_{T}}-1\right) .
\end{aligned}
$$

If $\Lambda=E\left[V_{2} \mid \Phi_{\mathrm{T}}\right]$, the first part of the proof shows that $F_{s}\left(\frac{\Lambda+X_{i}^{\mathrm{O}}}{X_{\mathrm{T}}}-1\right)$ increases with the market-mispricing factor $(\rho)$, and, hence, the probability of a cash acquisition decreases.

Parts i) and iii) are also found in RKV's original model. The reason the probability of a merger increases is not that the target does not revise its estimate of the bidders' true value. Rather, it does not revise them enough. Consider an overvalued target and assume that the overvaluation is solely due to marketwide overvaluation (i.e., $\rho>0, \psi_{\mathrm{T}}=\varepsilon_{\mathrm{T}}=0$ ). The target knows it is overvalued, but does not know if it is due to marketwide or industry- or firm-specific overvaluation. So, being a Bayesian updater, the target expects that all of these are positive. This prompts the target manager to revise the expectation of all other firms' true value downwards, to something below their market value. Now, assume that it gets one bid, that this bidder's synergy is zero (so $V=X_{\mathrm{T}}$ ) and that it is also only affected by marketwide misvaluation. 
The bidder bids its true valuation, but due to the marketwide misvaluation, the market value of its stock bid is higher than $X_{\mathrm{T}}$. Given its first revision of the bidder's market value, the target's estimate of the bid is less than the market value. However, since the manager's best estimate is that some of its own misvaluation stems from firm-specific and industry-specific misvaluation, the bid still appears higher than $X_{\mathrm{T}}$. Given this, the target manager's best estimate is that a part of the high bid value is that its estimate of the bidder's true value is still inflated, prompting a further downward revision, but it still puts some probability on the possibility that the synergy is positive and, therefore, that accepting the bid is profitable. In the end, even if the target works diligently to estimate the bid's true value, it still ends up overestimating it. A consequence of this is that, all else equal, more "bad" deals are made during times of market overvaluation, and the average synergy can even be negative. ${ }^{17}$

The proposition's second part stems from the assumption that managers' private information allows them a better estimate of firms in the same industry. While marketwide overvaluation inflates the estimates of bids from firms in other industries, it does not affect bids coming from within the target's own industry. Since it benefits bidders from other industries, not only do firms from within the target's industry not benefit from the overvaluation, it actually ends up hurting their chances of winning since they are now more likely to lose to a firm from another industry. Parts i) and ii) of Proposition 7 thus imply that marketwide overvaluation can cause merger waves, and that these waves occur between industries.

The last part of the proposition states that market misvaluation will decrease the share of cash acquisitions. Misvaluation does not affect what a bidder is willing to pay in cash, but it affects the price set by an accepted stock bid;

\footnotetext{
${ }^{17}$ That models of misvaluation can generate waves of bad mergers is an important complement to neoclassical models. SV point out that neoclassical theory predicts mergers to be profitable on average, but that the evidence for this is mixed. Ravenscraft and Scherer (1987), and Servaes (1996) find that the mergers undertaken during the 1960s did not lead to any improvements in profitability. Kaplan (1989) and Healy, Palepu and Ruback (1992) find evidence that the mergers in the 1980s merger wave increased profitability.
} 
thus, it is less likely that any firm will have a high enough synergy to be willing to compete with the stock-auction winner. In the same fashion, the target overvalues more firms when the market is overvalued, so, according to Lemma 5 , it is less likely that any firm will offer a cash bid, even when the stand-alone value of the target is the reservation price in the cash auction. ${ }^{18}$

The situation is reversed when the target itself, or the target industry, overvalued. The target still acts in the manner described before, but since the same overvaluation factor does not affect the stocks of other firms or firms from other industries, the target tends to undervalue stock bids.

Proposition 8 A more overvalued target industry or target itself increases the probability of i) a merger not occurring, ii) the merger being within the industry, and iii) the merger being paid in cash.

Proof. i) The expected values of bids that do not come from the target's industry are decreasing in the misvaluation of the target's industry $\left(\psi_{\mathrm{T}}\right)$ and the target itself $\left(\varepsilon_{\mathrm{T}}\right)$ since $\left(1+s_{i}\right)$ is affiliated with $\frac{\left(1+s_{i}\right)\left(1-\varepsilon_{\mathrm{T}}\right)\left(1-\psi_{\mathrm{T}}\right)}{\left(1-\varepsilon_{i}\right)\left(1-\psi_{k}\right)}$, which is strictly decreasing in $\psi_{\mathrm{T}}$ and $\varepsilon_{\mathrm{T}}$. Hence, it is less likely that any stock bid fulfills (12), and since cash bids are not affected by misvaluation, the overall probability of a merger decreases.

ii) The second part follows immediately from the first part: Since the target knows the true value of bids from its own industry, one of these is more likely to win the stock auction when the expected value of other bids decreases.

iii) The third part of the proposition is proven in the same way as the third part of Proposition 7, and by noting that $\Lambda \equiv \max \left\{E\left[V_{2} \mid \Phi_{\mathrm{T}}\right], X_{\mathrm{T}}\right\}$ is decreasing in $\psi_{\mathrm{T}}$.

RKV also includes the second part of the proposition; however, it is somewhat different. First, in RKV, the likelihood of a within-industry acquisition increases in the misvaluation of the target's sector, but it decreases in the target's firm-specific misvaluation factor. Second, in RKV, increased sector overvaluation increases the targets estimate of bids from its own industry, but decreases

\footnotetext{
${ }^{18} \mathrm{RKV}$ show that shared misvaluation can cause merger waves.
} 
its estimate of bids from all other industries. In this model, the estimates of bids from the same industry are unaffected since the target manager knows their true value, but we still have the effect that bids from other industries are estimated to be less valuable. Thus, within-industry mergers are more likely because firms from the same industry are less likely to lose to outside bids when the sector is overvalued, but the effect is weaker than in RKV.

Proposition 9 A more overvalued bidder is i) more likely to win and ii) and more likely to pay in stocks.

Proof. If we look at (8)-(11), we see that the conditioning variables are all increasing in the misvaluation factors affecting firm $i\left(\psi_{k}, \varepsilon_{i}\right)$, so it follows from Lemma 3 that $E\left[V_{i} \mid \Phi_{\mathrm{T}}\right]$ increases with $i$ 's overvaluation. For all $j \notin k, \psi_{k}$ enters only in the second expression's numerator, and we can once more use Lemma 3 to conclude that the target's estimates of all other bids are decreasing in the same variables. For firms in the same industry, the same holds with regard to $\varepsilon_{i}$, but not with regard to $\psi_{k}$. If $j \in k$, then $\psi_{k}$ cancels out in the second expression but appears in the first. We can here use that firms are ranked symmetrically within an industry, and that the within-industry ranking is $\frac{\left(1+s_{i}\right)}{\left(1-\varepsilon_{i}\right)\left(1-\psi_{k}\right)(1-\rho)}$, to conclude that the within-industry ranking is unaffected. Finally, since $E\left[V_{i} \mid \Phi_{\mathrm{T}}\right]$ increases, it is less likely to be challenged by a cash offer when it wins.

The second part of the proposition follows from the first part of the proof and Lemma 5.

The proposition contains several important empirical predictions. Proposition 8 shows that cash is more likely when the target is overvalued, which sets it apart from SV's model where undervaluation is a necessary condition for a cash acquisition. Therefore, it provides a tool to compare "managers acting in their own interest" and "managers acting in the interest of shareholders."

The other set of predictions regards the validity of the assumption of firms having better information about their industry peers. Taken together, Propositions 8 and 9 suggest that sector-level overvaluation may create merger waves between industries, but not within them. However, if the target manager has 
no informational advantage regarding the firms in her own industry (she observes $M$ but not $X$ ), then the estimates of these bids are increasing in $\psi_{\mathrm{T}}$. This means that sector-level overvaluation increases merger activity also within the overvalued industry. Similarly, the probability of a stock acquisition could go either way; it would decrease for between-industry mergers but increase for within-industry mergers.

Taken together, Propositions 7-9 show that the effects of overvaluation and undervaluation are not straightforward - highlighting both the importance of specifying on which level misvaluation affects a firm, and the need to account for both acquirer and target misvaluation simultaneously. Consider, for example, an overvalued target. When the overvaluation is due to firm or industry overvaluation, a takeover is less likely because the target undervalues stock bids. In contrast, when the overvaluation is due to the whole market being overvalued, the probability of a takeover increases because the same misvaluation also inflates the stock bids. That is, overvaluation that the target does not share with a bidder decreases the likelihood that the bidder wins the auction unless the target and the bidder are in the same industry.

However, a prediction from Propositions 8 and 9 is that the overvaluation of the acquirer is, on average, greater than the overvaluation of the target when the firms are from different industries, but that the relative difference is of no importance for within-industry mergers. Similarly, Ang and Chen (2006) find that the chance of a successful acquisition increases in the overvaluation of the bidder, and Edmans, Goldstein, and Jiang (2012) show that undervaluation increases the probability that a firm is acquired. In addition, Rhodes-Kropf, Robinson, and Viswanathan (2005), and Dong, Hirshleifer, Richardson, and Teoh (2006) provide evidence that acquirers are more overvalued than targets. Rhodes-Kropf, Robinson, and Viswanathan (2005) find that misvaluation difference is larger for between-industry mergers, and Komlenovic, Mamun, and Mishra (2011) find that misvaluation has a stronger effect on merger activity between industries than it has on merger activity within industries. 


\subsection{Changing the opportunity cost of cash}

So far, the analysis has concerned the effects of changes in misvaluation, but it has ignored the effects of changes in the opportunity cost of cash payments. It turns out that changing the opportunity cost of cash not affects the share of deals paid in cash, it also affects the share of mergers occurring within industries.

Proposition 10 Increasing the opportunity cost of cash i) reduces the probability of a merger occurring, ii) reduces the share of mergers paid in cash, and iii) increases the share of within-industry mergers.

Proof. i) The opportunity cost of cash does not affect the stock-auction stage. Using (12) and (13), the probability of a merger is

$$
\mathbb{P}\left\{\max _{i}\left[E\left[V_{i} \mid \Phi_{\mathrm{T}}\right], V_{i}-X_{i}^{\mathrm{O}}\right] \geq X_{\mathrm{T}}\right\} .
$$

Since $\max _{i}\left[E\left[V_{i} \mid \Phi_{\mathrm{T}}\right], V_{i}-X_{i}^{\mathrm{O}}\right]$ is decreasing in $X_{i}^{\mathrm{O}}$ for all $i$, the probability of a merger is decreasing in the opportunity cost of cash.

For the second result, the probability of a stock merger $\left(\mathbb{P}\left\{E\left[V_{i} \mid \Phi_{\mathrm{T}}\right] \geq\right.\right.$ $\left.\left.\max _{i}\left[V_{i}-X_{i}^{\mathrm{O}}, X_{\mathrm{T}}\right]\right\}\right)$ increases by $X_{i}^{\mathrm{O}}$ while the probability of a cash merger $\left(\mathbb{P}\left\{V_{i}-X_{i}^{\mathrm{O}} \geq \max _{i}\left[E\left[V_{i} \mid \Phi_{\mathrm{T}}\right], X_{\mathrm{T}}\right]\right\}\right)$ decreases, meaning that the share of cash mergers decreases.

The third result follows from Corollary 6, which implies that firms from the target's own industry are not directly affected by the opportunity cost of cash. A within-industry merger occurs if

$$
\exists j \in \mathcal{T} \text { s.t. } V_{j} \geq \max _{i \notin \mathcal{T}}\left\{E\left[V_{i} \mid \Phi_{\mathrm{T}}\right], V_{i}-X_{i}^{\mathrm{O}}, X_{\mathrm{T}}\right\},
$$

where the right-hand side is decreasing in $X_{i}^{\mathrm{O}}$.

Corollary 11 Decreasing the opportunity cost of cash increases the probability of a merger more in more undervalued markets.

Proof. This follows from the first parts of Propositions 7 and 10: Decreasing the opportunity cost only increases the merger probability if the target deemed no stock bid good enough. 
If it becomes cheaper for firms to use cash, then more firms will do so. This is what the empirical literature finds (see, e.g., Harford, 2005; Blomkvist, 2014). Note that if firms are financially constrained, then their opportunity costs change with their investment opportunities. If a bidder's investment opportunities improve, then this alternative use of cash becomes more attractive, so the synergy factor needed to induce a cash offer increases. Thus, we would expect to see fewer cash-financed mergers during times of good investment opportunities; in fact, Proposition 10 predicts that we will see fewer mergers in total during these periods. ${ }^{19}$

The number of within-industry mergers increases with the opportunity cost of cash because cash is a way for firms to circumvent the problem of misvaluation. Proposition 6 states that firms from the target's industry will never make cash offers, so the cost of cash does not affect them directly. However, it does affect them indirectly: When the cost of cash increases, firms from outside the target's industry are willing to offer less cash to acquire the target, so it is less likely for a related firm to win the stock auction only to lose to a subsequent cash bid.

That the effect on merger activity from reducing the opportunity cost of cash is stronger during times when the market is undervalued comes from the fact that marketwide overvaluation increases the likelihood that the target will accept a stock offer. Decreasing the opportunity cost of cash can only lead to a merger where before there was none if no one won the stock auction - i.e., if the target manager deemed none of the stock offers sufficiently high. Otherwise, it may only turn an stock acquisition into a cash acquisition. Since marketwide overvaluation increases the manager's estimate of all stock offers (apart for those offers coming from the same industry), the target is more likely to accept a stock offer during times of market overvaluation, so it is less likely that lowering the alternative cost of cash leads to an acquisition when there otherwise would not

\footnotetext{
${ }^{19} \mathrm{By}$ the same reasoning, it is straightforward to prove that firms with good outside investment opportunities are less likely to make an acquisition, and, when they do, they are more likely to pay with stocks. This is in line with the empirical findings of Di Giuli (2013).
} 
have been one. Corollary 11 thus predicts that a reduction in financing costs has a greater effect on the number of mergers when the market is undervalued.

\section{Conclusion}

Fluctuations in merger activity can occur for many reasons. According to neoclassical theory, economic and financial shocks cause merger waves. In this theory, technological innovations and regulatory changes create profitable opportunities to reallocate assets between owners, and innovations to firms' financing conditions make previously unprofitable acquisitions profitable. In what have been called behavioral theories, the driving force is instead asymmetric informa-

tion. In this paper, I have modified and extended RKV's behavioral model by assuming that firms can use their private information to get a correct estimate of the true value of firms in the same industry, and that all firms can make cash offers but are financially constrained to differing degrees.

Assuming that managers have information about the true value of their industry peers allowed me to derive results concerning the effect of marketwide misvaluation, predicting that not only are mergers more likely when the market is overvalued, but that they are also more likely to occur between than within industries. Another new prediction is that the acquirer is more likely to be from the same industry as the target when the target is overvalued at the firm level, while the opposite is true when it is undervalued. In the model, easing the credit conditions leads to more mergers since it is then cheaper for firms to sidestep the asymmetric-information problem and pay with cash when the target underestimates their true value. Since the problem of asymmetric information exists between industries, the model predicts that lower capital costs will lead to more mergers occurring between industries. Similarly, if firms are financially constrained they might have to choose between making an acquisition and making other investments, so the opportunity cost of spending cash on acquisitions is therefore higher during times of good outside investment opportunities. The model thus predicts that mergers are less common during these periods, 
and that this decline in merger activity is due to a decline in between-industry mergers.

The last result of my model pertained to how the effects of lowering the cost of paying with cash depend on market misvaluation. Since the manager of the targeted firm is more likely to underestimate bids during times of market undervaluation, she is more likely to decline all bids during these times. Thus, making it cheaper for firms to bid with cash has a greater effect on the probability of a merger in these states of the world.

\section{Acknowledgements}

This paper has benefited from useful comments from Frederik Lundtofte, Lars Persson, Sven-Olof Fridolfsson, and from participants in seminars at Lund University and IFN.

\section{References}

Andrade, G, M Mitchell, and E Stafford. 2001. New evidence and perspectives on mergers. Journal of Economic Perspectives 15, 103-20.

Ang, J, and Y Cheng. 2006. Direct evidence on the market-driven acquisition theory. Journal of Financial Research 29(2), 199-216.

Berkovitch, E, and M Narayanan. 1990. Competition and the medium of exchange in takeovers. Review of Financial Studies 3(2), 153-74.

Blomkvist, M. 2014. The effects of financial constraints on merger activity. In Essays on Market States, Firm Growth and Corporate Finance Decisions, $\mathrm{PhD}$ dissertation. Hanken School of Economics.

Caplin, A, and B Nalebuff. 1991. Aggregation and social choice: A mean voter theorem. Econometrica 59, 1-23.

Di Giuli, A. 2013. The effect of stock misvaluation and investment opportunities on the method of payment in mergers. Journal of Corporate Finance 21, 196-215. 
Dong, M, D Hirshleifer, S Richardson, and S Teoh. 2006. Does investor misvaluation drive the takeover market? Journal of Finance 61(2), 725-62.

Eckbo, E, R Giammarino, and R Heinkel. 1990. Asymmetric information and the medium of exchange in takeovers: Theory and tests. Review of Financial Studies 3, 651-75.

Edmans, A, I Goldstein, and W Jiang. 2012. The real effects of financial markets: The impact of prices on takeovers. Journal of Finance 67, 933-71

Eckbo, E, T Makaew, and K Thorburn. 2016. Are stock-financed takeovers opportunistic? Working paper, Tuck School of Business Working Paper 2013121 .

Fishman, M J. 1989. Preemptive bidding and the role of the medium of exchange in acquisitions. Journal of Finance 44, 41-57

Gorbenko, S G, and A Malenko. 2014. The timing and method of payment in mergers when acquirers are financially constrained. MIT Working Paper.

Gort, M. 1969. An economic disturbance theory of mergers. Quarterly Journal of Economics 83, 624-42.

Hansen. 1987. A theory for the choice of exchange medium in mergers and acquisitions. Journal of Business 60, 75-95.

Harford, J. 2005. What drives merger waves? Journal of Financial Economics 77, 529-60.

Healy, P, K Palepu, and R Ruback. 1992. Does corporate performance improve after mergers? Journal of Financial Economics 31(2), 135-75.

Jovanovic, B, and P Rousseau. 2002. The Q-theory of mergers. American Economic Review 92(2), 198-204.

Jovanovic, B, and P Rousseau. 2008. Mergers as reallocation. Review of Economics and Statistics 90(4), 765-776.

Kaplan, S. 1989. The effects of management buyouts on operating performance and value. Journal of Financial Economics 24(2), 217-54.

Kolev, K, J Haleblian, and G McNamara. 2012. A review of the merger and acquisition wave literature: History, antecedents, consequences and future directions. In D Faulkner, S Teerikangas, and R Joseph (Eds.), Handbook of 
Mergers and Acquisitions. Oxford, UK: Oxford University Press.

Komlenovic, S, A Mamun, and D Mishra. 2011. Business cycle and aggregate industry mergers. Journal of Economics and Finance 35, 239-59.

Liu, T. 2012. Takeover bidding with signaling incentives. Review of Financial Studies 25(2), 522-56.

Milgrom, P R, and R J Weber. 1982. A Theory of auctions and competitive bidding. Econometrica 50, 1089-122.

Mitchell, M, and J Mulherrin. 1996. The impact of industry chocks on takeover and restructuring activity. Journal of Financial Economics 41, 193229 .

Ravenscraft, D J, and F M Schere. 1987. Mergers, Sell-offs, and Economic Efficiency. Washington, DC: Brookings Institution.

Rhodes-Kropf, M, D T Robinson, and S Viswanathan. 2005. Valuation waves and merger activity: The empirical evidence. Journal of Financial Economics 77, 561-603.

Rhodes-Kropf, M, and S Viswanathan. 2004. Market valuation and merger waves, Journal of Finance 59, 2685-718.

Servaes, H. 1996. The value of diversification during the conglomerate merger wave. Journal of Finance 51(4), 1201-25.

Shleifer, A, and R W Vishny. 2003. Stock market driven acquisitions, Journal of Financial Economics 70, 295-311.

Stein, J. 2003. Agency, information and corporate investment. In G Constantinides, M Harris and R Stulz (Eds.), Handbook of the Economics of Finance, volume 1. Amsterdam, Netherlands: Elsevier.

Vermaelen, T, and M Xu. 2014. Acquisition finance and market timing. Journal of Corporate Finance 25, 73-91. 